\title{
The implementation of BIM In a large European construction company
}

\author{
Ger Maas $^{\mathrm{a}}$ \\ ${ }^{\text {a }}$ Director of Strategy at Royal BAM Group, Bunnik \\ The Netherlands and \\ Chair Construction Management and Engineering at \\ Eindhoven University of Technology \\ (G.J.Maas@tue.nl)
}

\begin{abstract}
-
Background: Information Technology (IT) has reached a level of maturity, where IT can really meet the complexity of the construction industry. IT has reached the ability to support construction not just any more in the facilitating processes as financial services and human resources management (HR), but also to play a key role in the primary process due to the development of the building information modeling (BIM). However, implementation of BIM in a company is still an challenging exercise. Purpose of this paper: The development of an implementation strategy based on the needs of project support. Method: Desk research gives insights in the roles and phases in a project, levels of hierarchy in a company and two case studies in two large European construction companies deliver insight in the actual situation. Results \& Discussion: The complexity of BIM implementation will be presented in a clear analysis of BIM for the different roles, activities, phases of an building project. Moreover a BIM implementation approach will be presented useful for small and large construction companies.
\end{abstract}

Keywords -

Building and Architecture, BIM, Construction

\section{Introduction}

Latest IT such as BIM is rapidly spreading to architecture, civil engineering, engineering and maintenance with the aim of simplifying complex system in buildings and facilities, minimizing operation cost, providing high value services and advancing Facility Management. In particular, BIM-based management framework design to assist the development of sensor information operation system, which adds convenience to facility maintenance and management, has emerged as a key issue.

In addition, a technology for real-time connectivity of geographic information systems (GIS) with building information modeling (BIM) linking technology, sensor information and three-dimensional spatial information in smart construction operation and management is necessary.
This very technology, which is a smart building technology converging building, electricity and electronic and IT, will have a big impact on construction IT convergence industry like integrated building systems IBS. BIM once developed will evolve into a whole newly applied science around component technology, around hitech sensor systems, IT and architectural engineering. Various information about the building itself and others acquired via numerous sensors in a facility and equipment will ensure managing in-building resource effectively and maintaining energy optimally. Development of sensor maintenance hardware/software linked to mobile devices will also become more active.

Development of a sensor maintenance technology based on context resource management linked with BIM system and establishment of a standard information management system linked with national standard BIM systems are also expected to gain further momentum.[2].

While the use of BIM is usually limited to design and construction, owners and facility managers have realized its potential and persist on inheriting BIM models for further use. Figure 1 illustrates the potential uses of BIM in different phases of any constructed project during its life cycle. Since Facility Management (FM) activities are information intensive and all related decision making processes involve vast amounts of data, having real-time and efficient access to information is essential to make the maintenance of the facility more feasible.

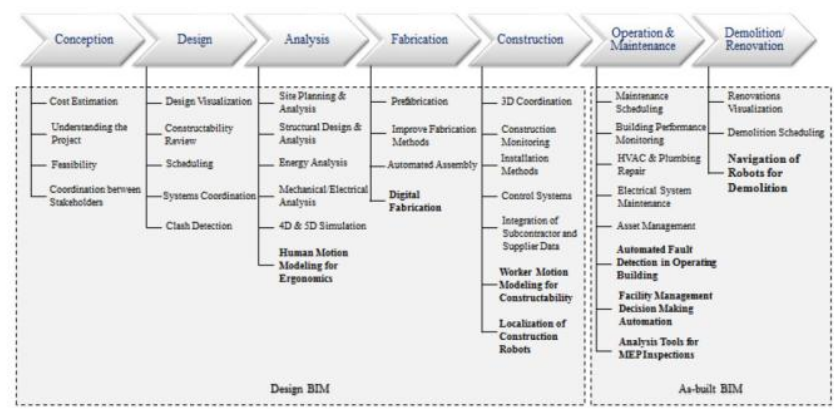

Fig. 1 Potential applications of BIM during a facility's lifecycle. [1] 
Figure 1 shows the potential role that a BIM tool can play in the life cycle of a building more than just replacing the traditional 2D drawings. It supports information management and decision making during the whole life of the building.

The survey of Lui and Issa [3] shows results, that indicate that the industry practitioners believed that maintainability issues should be considered in the design and construction phases.

BIM has changed the way the Architecture, Engineering and Construction industry (AEC) industry communicates and cooperates. Knowledge sharing between the facility management and design professionals has become possible with BIM. BIM technology has been used effectively in the design and construction phases. There is a need to expand BIM beyond the design and construction phases and to consider using BIM for facility management such as in maintenance activities. However, the research on BIM use for Facility Management is lagging behind the study of BIM in design and construction phases.

Maintenance costs, although the largest cost over a building's life cycle, are currently rarely considered in the early design phase. Some design errors that make maintenance activities impossible to perform are always hard to visualize in the design phase. As the next advancement for Facility Management (FM), design for maintenance (D4M) should be considered in the early design phase.[3].

The authors in [4] presented the use of BIM in design optimization and design-scenario development and the development of an automated Decision Support System (DSS) for optimizing the selection of the best design according the Leadership in Energy and Environmental Design index (LEED). This LEED index has an upgrade for decisions in Existing Buildings (LEED-EB). The DSS provides decision makers with the flexibility to minimize the required total upgrade costs to achieve a specified

LEEB-EB certification level such as gold or silver; or maximize the number of LEED-EB points that can be achieved within a specified limited budget. The developed DSS utilized linear programming to perform the optimization computations because of its guarantee to generate a global optimal solution and its reasonable computational time and effort compared to other optimization techniques. An application example was analyzed to illustrate the use of the developed DSS and evaluate its performance. The developed DSS was able to identify the optimal upgrade decisions for minimizing total upgrade costs for achieving Certified and Silver LEED-EB levels. Furthermore, the DSS was able to identify the optimal upgrade decisions for maximizing the number of LEED-EB points within a range of specified upgrade budgets. The DSS offers unique and important capabilities to aid decision makers in achieving the highest benefits for upgrading their buildings within the specified budgets. It provides a practical tool to evaluate and optimize various green upgrade options effectively and efficiently.[4].

\section{Case studies}

\subsection{NCC Sweden}

Patrick Lindvall, NCC Construction Group Sweden, reported the strategies adopted by NCC and introduces how they have integrated corporate and 'legacy data' into the BIM for use during the Build Phase.

NCC is today implementing the internal services and data layers required to reach maturity Level 3 BIM, ensuring they have the infrastructure to support the organizations use of Virtual Design and Construction not only today but tomorrow as well.

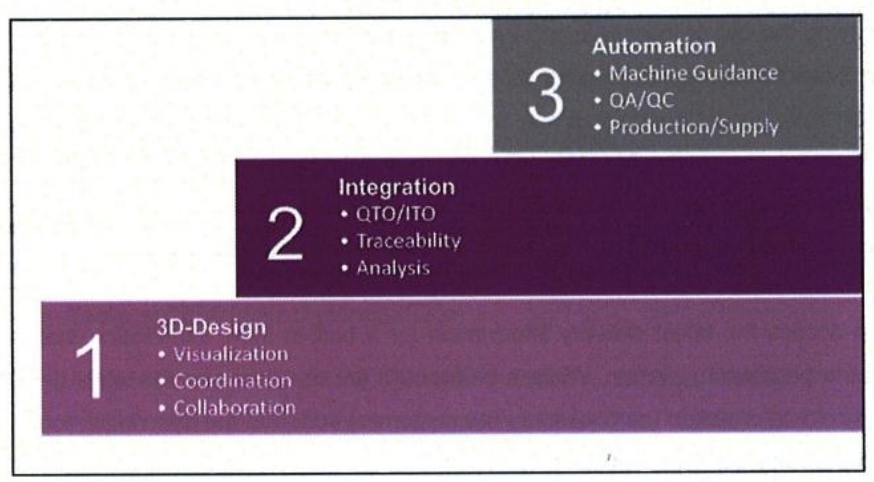

Figure 2: NCC's three stepped approach to VDC, with some typical uses. [5]

According figure 2: The 1e implementation level contains 3D design with visualization, coordination and collaboration options. The $2 \mathrm{e}$ level adds the integration of modules in the 3D model for quantity take of traceability of design decision and analysis of the performance of the current design. Level 3 adds modules for machine guidance with Computer aided Design and Computer aided Manufacturing (CAD-CAM) and for quality assurance and quality control as well as production and supply information.

As stated by Lui and Issa (3), the use of BIM need to be extended along the whole life cycle of a building to support the use, the facility management and the maintenance of the building.

\subsection{BAM, The Netherlands}

BAM's vision on BIM is that with BIM the information of a building project will be secured in one or more 3D models and databases. By relating the 3D models with the dimensions, time, budget requirements, maintenance data, etc. the information of various expertises will be stored unambiguously BIM created. 
BIM creates opportunities for collaboration during the whole life cycle of the project.

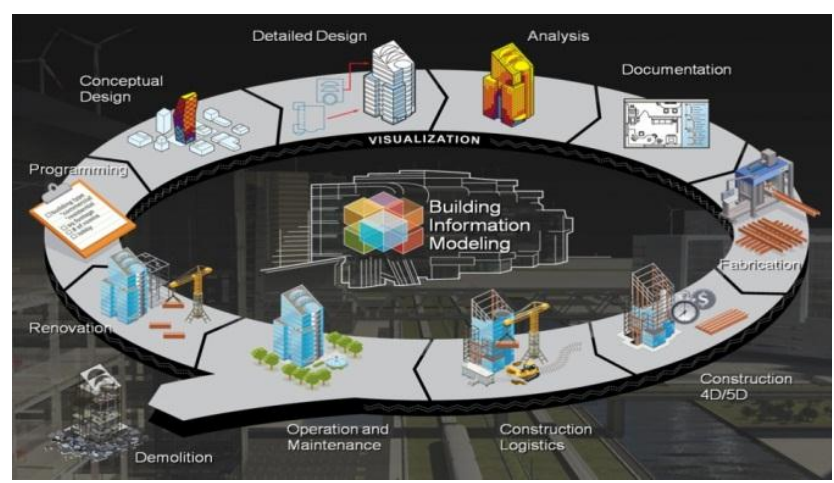

Figure 3: BIM in the life cycle

Figure 2 shows the life cycle of a building from program to design, construction, demolition or renovation and re-programming again. The circle isn't closed yet, but efforts are made to improve the use of BIM and to increase the value during the whole life cycle. At the moment most of the influence of BIM has been limited to design and execution.

BIM supports on the projects:

- To develop opportunities and to limit risks;

- To create insights in complex structures and bottle necks;

- To promote integral and multidisciplinary working;

- To collaborate simultaneously;

- To reduce failure costs;

- To shorten the project time of the building process;

- To enlarge the accuracy;

- $\quad$ To improve interface management;

- To save resources (paper).

Some projects examples are:

At Leeds Arena (UK) some improvements were achieved:

- Reduction of failure costs by interface management;

- Saving of manhours by more efficient working;

- Limiting the number of 2D drawings by using 3D models;

The use of BIM in project management and execution will be extended, when a contractor has a long time commitment to a project or if the owner likes to use design and construction data during the life span of the use of a building. The next use of BIM is implemented now:

Simulation of the use phase by comparing energy costs and maintenance efforts as a consequence of different design solutions.

- Simulation of different design and construction solutions and their consequences of aspects as logistics and cash flow.
- $100 \%$ validation and verification at the moment of handover, transparent for the owner. It avoids hidden failures, that haave to be solved during the operation phase.

- $\quad$ By linking maintenance management systems is real time reporting on key performance indicators (KPI) possible.

- As build data with output specifications and technical specifications are conditionally for a quick response in case of a failure during the use and operation.

Generally the following BIM functions are usefully used in Royal BAM Group companies: visualization, engineering, 3D reinforcement, 4D simulations, clash detection, measurements, global positioning systems (GPS), steering of equipment, quantity calculations, CAD-CAM connection.

The use of BIM needs initiatives at 4 levels in the company:

1. The employee

2. The departments

3. The group companies and

4. The company as a whole.

At the level of individual employees and at the level of departments applications for the following activities have to be developed: planning, design, scheduling, cost estimation, work preparation, execution, operation and maintenance.

Facilitating effort has to be spent at the level of group companies: development of BIM techniques, knowledge and experiences, implementation in projects, influence at HR and investment in ICT.

At group level: overarching facilitation is necessary as: development of BIM techniques, sharing knowledge and experiences and ICT investments. Every hierarchical level has its own distinguished responsibilities. The initiatives at the different levels have to be related very carefully.

\section{Proposal for BIM implementation program}

The NCC BIM development program as reported [5] presents 3 steps.

In case of BAM a few mismatches with the 3 steps development program can be reported from this BAM case study.

Firstly in a large company the development speed is not equal in all countries where the company has activities. Market circumstances, the involvement of other parties in the supply chain and local regulations influence the implementation speed of BIM as well as the possibilities to use BIM on site.

Secondly: the more a company has been involved in the life cycle of a project, the more useful it is to invest in BIM applications. The traditional use of BIM for design support is usually the start, but more and more you can 
see the link of the need of Facility Management data to the design phase. The gathered data from Facility Management can be useful as design input as well. It creates the option to make scenario analyses in the early stage of a project. This needs to be added to the NCC development steps.

In case of BAM the following phases of the implementation of BIM can be discovered.

The first step is always the use of 3D models for visualization, coordination and engineering.

Secondly the use of an information model for quantities, cost estimation, save specifications and verification can be introduced.

Thirdly documents with its build information ready for maintenance support can be created.

Fourthly model based scheduling, planning and validation of requirements is reachable.

The fifth phase is to use full size BIM models to create simulations for different aims such as optimizing cash flow, performance requirements and logistics on site.

The last phase is to have fully integrated BIM support in your project. All information that people need in the life cycle can be extracted from the BIM model.

To steer the implementation of all BIM activities the following process is used in the BAM case.

\begin{tabular}{|c|c|c|c|c|c|c|}
\hline & $\begin{array}{l}\text { 3D } \\
\text {-Visualisation } \\
\text {-Coordination } \\
\text {-Engineering }\end{array}$ & $\begin{array}{l}\text { Model based } \\
\text {-QTO } \\
\text {-Estimation } \\
\text {-Specifications } \\
\text {-Verifications }\end{array}$ & $\begin{array}{l}\text {-Handover } \\
\text { As Build } \\
\text { to O\&M } \\
\text {-Deploy As } \\
\text { Maintained } \\
\end{array}$ & $\begin{array}{l}\text { Model based } \\
-4 D \text { planning } \\
\text {-Progress } \\
\text { monitoring } \\
\text {-Validation } \\
\end{array}$ & $\begin{array}{l}\text { Simulations to } \\
\text { optimize } \\
\text {-Cash flow } \\
\text {-Performance } \\
\text {-Logistics }\end{array}$ & $\begin{array}{l}\text { Full } \\
\text { Integrated } \\
\text { BIM } \\
\text { Support }\end{array}$ \\
\hline 2020 & 100 & 100 & 100 & 100 & 100 & 100 \\
\hline 2019 & 100 & 100 & 100 & 100 & 90 & 90 \\
\hline 2018 & 100 & 100 & 100 & 90 & 80 & 70 \\
\hline 2017 & 100 & 100 & 90 & 80 & 70 & 60 \\
\hline 2016 & 100 & 90 & 80 & 70 & 60 & 50 \\
\hline 2015 & 100 & 60 & 50 & 40 & 30 & 20 \\
\hline 2014 & 50 & 30 & 30 & 20 & 10 & 10 \\
\hline 2013 & 20 & 10 & 10 & 5 & 5 & 5 \\
\hline
\end{tabular}
(2013)

Figure 4 shows horizontal the 6 successive phases of the maturity of the use of a BIM model. The order is in line with a certain increase of complexity and integration, as described above. The vertical axe shows the years of implementation. The numbers present the percentage of the projects that are using the tools in the different phases. These numbers are the targets, that have been set and that will steer the implementation.

\section{Lessons}

It creates transparency in a company to distinct activities in BIM development process for the different hierarchical levels in a company. The employee and his/her department hove to do a lot of development work for all modules of BIM to integrate these modules in other company systems.

Facilitation of the implementation is necessary at group company and at group level to share knowledge and experiences and to decide on ICT investements.

The differences in complexity of successive BIM modules delivers a guidance in the order of the implementation process. The more mature, employees and organizations are in the use of BIM, the furher they can go in the implementation and use of BIM tools from $3 \mathrm{D}$ visualization and design through cost and quantity estimation and as build information to model based planning, design simulation and full integrated BIM support.

\section{References}

[1] Golabchi, A., Aklula, M. and Kamat, V.R. Leveraging BIM for automated fault detection in operational buildings, Proceedings of Isarc, Montreal, 2013

[2] Lee, S. and Sung-Ah, K. Real time facility management system framework based on building information modelling and web of things. Proceedings of ISARC, Montreal, 2013

[3] Liu, R. and Issa, R.R.A. BIM facility Management: design for maintainability with BIM tools. Proceedings of ISARC, Montreal, 2013

[4] Abdallah, M., El-Rayes, K. and Liang, L. Automated decision support system for optimizing the selection of green building measures. Proceedings of ISARC, Montreal, 2013

[5] Lindvall, P., Extending the information model lifecycle. Proceedings Lake Constance 5D conference, 2013

[6] Maas, G., BIM binnen BAM, BIM policy document 2013 of Royal BAM Group, The Netherlands.

[7] Quadt, M., Marriage in construction projects, proceedings Lake Constance 5 D conference, 2013 